\title{
Formation of the foreign language training system in the context of its conceptuality
}

\author{
Agzam A. Valeev - Larisa I. Tararina - Maria A. Khvatova - Olga O. \\ Shalamova
}

DOI: 10.18355/XL.2020.13.04.15

\begin{abstract}
Currently, foreign language skills become relevant not only from the point of view of professional necessity but also to obtain the ability to successfully integrate into any multicultural environment in general and the international professional community in particular. In this regard, the article presents the following: A conceptual model of training a foreign language in the university education; The formulation of the main objectives of teaching a foreign language on the conceptual basis; Aspect disclosure of the conceptualization of training a foreign language; Feature description of information and communication support of training a foreign language in a university; emphasis on the opportunity of developing skills in the use of vocabulary in foreign language communication; justification for the use of the conceptual approach to the formation of foreign language activities.
\end{abstract}

Key words: foreign language, lexical structure, conceptual education, information and communication technologies, university, students, lecturer

\section{Introduction \\ 1.1.Actualization of the Problem of the Foreign Language Training in the Context of its Conceptuality}

Currently, the world is undergoing complex and controversial changes, which also concern the development of foreign contacts in almost all spheres of activity. And in the context of globalization of world processes, the knowledge of foreign languages is the most important condition for success for an expanding circle of professionals. Meanwhile, the difference between "knowledge of the language" and "proficiency in the language" becomes more apparent; i.e. the competitiveness of a specialist is not determined by the knowledge of many foreign words and grammar rules, but by practical communication skills (Iskhakov et al., 2019). Hence, the success of an individual is predetermined by his ability to organize productive communication with people (Masalimova et al., 2019). And from the point of view of a foreign language, this means the ability of an adequate understanding of the interlocutor and finding a "common language". In this regard, not teaching objectives, but developmental and educational ones came to the fore. Moreover, each university teacher has the task not only to help students to learn vocabulary, grammar and syntax, but also to introduce them to the culture of another nation, to form an understanding of foreign traditions and customs; to help in comprehending another worldview, etc. However, as the analysis of psychological and pedagogical literature has shown, in the context of the problem under study there are certain contradictions, for example, such as: the contradiction between the need to master the vocabulary of a foreign language to use it in real communication and the lack of a conceptual approach to such mastery; the contradiction between the cognitive potential of conceptual learning of a foreign language and its insufficient presence in the process of learning the vocabulary of a foreign language. Thus, there is a need to develop elements of a foreign language teaching methodology, taking into account the construction of a foreign language training system in the context of its conceptuality, which, in particular, is also determined by the fact that there are known difficulties regarding the attitude of

XLinguae, Volume 13 Issue 4, October 2020, ISSN 1337-8384, ISSN 2453-711X 
students to the learning process itself (Kvon et al., 2019). For example, this problem is reflected in the reluctance of some young people to learn a foreign language. To solve this problem, in particular, for the formation of motivation to learn a foreign language in various educational institutions, various educational models of teaching are used with the use of cultural and intercultural competences (Gapontsev et al., 2019). This problem also arises when assessing the level of motivation of students to master a foreign language, the level of preparedness for this process. That is why it is so important to conceptually approach teaching a foreign language as a whole and find the right balance between the language and the culture itself. It is also important to take into account the difference in language perception of students, as well as the focus of the whole group on the learning process, in particular, on achieving goals in the implementation of foreign language communication. However, the solution of this problem cannot be considered sufficient, given the problem of high-quality language professional training of students in all its versatility, especially taking into account the modern requirements for the formation of the personality of a specialist (Moskalenko et al., 2019). And these requirements imply, for example, not just fluency of young people in a foreign language, but also the development of a whole range of their competences, among which we would always consider cognitive, informational, communicative, cultural, and regulatory to be relevant, which implies creating a language environment for students foreign language speech communication.

\subsection{The Main Aspects of the Conceptualization of Foreign Language Teaching}

Undoubtedly, the main aspects of the conceptualization of teaching a foreign language are in one way or another connected with the mastering of knowledge about a foreign language and its structure; with the formation of verbal and cogitative activity; with the enrichment of vocabulary and grammatical structure of students' speech; with the formation of such necessary for cognitive activity skills, as the ability to identify, analyze, compare, classify language facts; to evaluate them in terms of standard; to carry out information retrieval, to extract and convert the necessary information, etc. And the achievement of all these goals by students often depends on the quality of both group and independent work. In this regard, the university forms on the conceptual basis a certain structure for teaching a foreign language, which necessarily includes (these aspects are discussed in detail later) foreign language teaching, the expansion of active vocabulary, the use of information and communication technologies, the formation of foreign language activities. These aspects are a multidimensional model of teaching foreign languages, which is built on the basis of the conceptual nature of teaching, which involves mastering students' understanding of the organization of a foreign language system; self-organization skills in the expansion of vocabulary in a foreign language; understanding of vocabulary with regard to its professional orientation; the ability to structure the lexical and grammatical material in foreign language communication; the ability to correctly use speech patterns in foreign language speech; goal-setting students to improve the quality of their foreign language activities. In addition, this educational model is based on a concept that integrates, in addition to cognitive competencies, the development of students' communicative abilities in a foreign language; intercultural competencies that promote adequate behavior in the cultural environment of a foreign language; competence of self-organization of self-study of a foreign language. This educational model on the conceptual basis of training a foreign language implies the creation of maximum conditions for organizing communication in a foreign language, supplemented by cultural aspects in order to create prerequisites for better interaction in a multicultural environment. All this is directed, in fact, to the development of students' natural behavior and mutual understanding in intercultural relations.

Speaking about the main aspects of the conceptualization of teaching a foreign language, we also mean that the cognitive development of students should be directly 
connected with the development of their emotional sphere, corresponding to a pragmatic perspective. Hence, the developed conceptual framework for teaching a foreign language creates a special educational space associated with a foreign language and taking into account its cultural context and the needs of students. At the same time, a holistic approach to structuring courses (modules) at each stage of education allows integrating all sorts of educational approaches and methodological techniques, resulting in social and cultural pedagogical tactics that stimulate student learning, thus solving various problems in new cultural and organizational conditions. Hence, this pedagogical tactic, which ensures the implementation of educational models, basically always supports the development of various educational scenarios in a foreign language, where the following components are combined: Teaching methodology, its methods, and techniques (for example, working together on a project in the language, business games modeling of thematic situations in the language, etc.); Information and communication technologies (for example, multimedia, social services and Internet services, computer tutorials, authentic video films, etc.); Educational formats (e.g., interactive lecture and seminar, distance learning, bilateral training, small/large groups, etc.). Thus, all this provides a general format for teaching a foreign language, taking into account the conceptual nature of this process in the conditions of the university, which is decided by teachers and methodologists throughout the entire period of students' education. And now various educational programs in a foreign language are being developed and implemented, connected not only with the development of language competencies among students, but also taking into account their future specialty, which is conditioned by the selection and systematization of educational material. In this regard, one of the conceptual foundations for the formation of the foreign language training system at a higher education institution is the creation of conditions for students' development of foreign language speech, for example, the organization of the natural language environment, when a foreign language is learned not only in class but also in the process of constant verbal communication with native speakers. All this, naturally, enriches and activates the stock of common foreign vocabulary, motivating students to organize communication in a foreign language.

\subsection{Conceptual Approach to the Formation of Foreign Language Activities}

When considering a conceptual approach to the formation of foreign language activities in the course of the study, the most productive methodological techniques for learning a foreign language were selected. So, gaming technologies are very relevant today, which can be used in high school at any level of education with the appropriate adaptation for the level of preparedness of each student. This may be, for example, a role-playing game of everyday content (aimed at forming speech etiquette), worldly content (related to the culture of behavior), an imitation business game (focused on developing the ability to organize communication in a foreign language), etc. In this regard, the conceptualization of the formation of foreign language activities is here to provide an opportunity to organize communication in a foreign language within a certain thematic storyline, where students are supposed to develop all types of speech activity. For example, it may be a certain interview of a student with an imaginary foreigner, during which the interlocutors exchange questions and answers. Or it can be organized in the form of a dialogue in a foreign language between the teacher and students (for example, during the formulation of the stated topic in the lesson). First, students formulate questions using interrogative words (for example, What ...? When ...? Where ...? Is it ...? How is it? ..., etc.), then the teacher writes these questions on the blackboard and asks other students try to answer them, arguing their assumptions. At the same time, the work can be varied. So, in the first column, questions that require a simple answer are written; the second

XLinguae, Volume 13 Issue 4, October 2020, ISSN 1337-8384, ISSN 2453-711X 
column contains questions requiring a detailed answer; in the third column, there will be questions that the students themselves cannot yet answer but would like to find answers to them. Then students listen to the proposed text for study and try to find confirmation of their assumptions about the stated topic. After this form of work, students begin to understand the main aspects of the topic being studied in this lesson. And this includes such a conceptual moment as the unfolding of the critical thinking process of students, when they analyze things and events with the formulation of reasonable conclusions with the aim of correctly applying them to various situations and problems. The use of critical thinking technology in foreign language classes contributes to the formation of students' communicative competence, providing comfortable conditions for their foreign language activities, stimulating their motivation to the practical use of a foreign language in everyday life. However, for more productive work of students, it is important that the language material contributes to the development of critical thinking of students; i.e. any remark of the teacher should activate the mental activity of students; so that no student remains indifferent to what is happening in the classroom.

Take, for example, such a technique as "brainstorming", which is aimed at developing a creative type of thinking, when the topic chosen by the teacher suggests various solutions to the problem considered in it. The most productive "brainstorming" is carried out in a group of students with no more than 5-7 people. And the main difficulty here is the organization of students' communication only in a foreign language. Therefore, before the "brainstorming", the necessary vocabulary, speech patterns and semantic tone of speech are worked out on the proposed topic. So, first, under the guidance of a teacher, a bank of ideas and various aspects of the problem are created. At the same time, any proposals are accepted (all this is fixed on the board). Then there is a collective discussion of the choice of the main idea and a proposal for it. At this stage, the teacher helps students to combine all the proposals in a single unit. Then a search is done for a selection of the most promising solutions. Thus, this technique can become a leading technique both at the stage of invoking reflection to one's own foreign language activity and as an important tactical stage of the occupation as a whole.

\subsection{Status of a problem}

In the lingua-methodical literature, ideas for the conceptualization of learning a foreign language have been developed. In this regard, the problems of teaching a foreign language from the point of view of the conceptuality of this process are found, in particular, in the works of E.V. Bondarevskaya (2000), M. Byram \& A. Feng (2004), O.M. Vinnikova (2016). Important studies that actualize the problem of the vocational orientation of learning a foreign language were the works of L.V. Golikova (2005), O.Yu. Iskandarova (2000), I.G. Kondrateva \& A.A. Valeev (2015). The development of aspects of the content and scope of language modality is discussed in the works of L.B. Boldyreva (1987), R Kern \& J.M. Schultz (2005), P.V. Sysoev (2006). Considering the psychological mechanisms for mastering foreign grammar, we used the ideas of Z.B. Devitskaya (2008), R.C. Gardner (1983), B.L. Liver (2000). In this connection, the works of N.V. Elukhina (2002), R.R. Khusainova \& A.A. Valeev (2018), E. Reid (2015) associated with the problem of teaching methods in training a foreign language were of great interest for us. Of great importance to us were also works related to the aspects of learning foreign languages of such authors as A.V. Babayants (2005), A.D. Ishkov (2004), V.S. Tsetlin (2000). This study was also based on such authors in the field of learning foreign languages as V.V. Grachev (2007), S.A. Iskrin (2004), Y. Zhang (2017). Of particular importance for this study were works on the development of the cognitive potential of students of such scientists as V.P. Ivanova (2013), A.N. Khuziakhmetov \& A.A. Valeev (2017), S.V. Kuzmina \& N.V. Vlasihina (2013). The use of modern approaches in teaching a 
foreign language is discussed in the works of I.N. Kaloshina (2000), M.V. Nazarova \& A.A. Valeev (2017), E.G. Sabirova at al. (2018). In this study, special attention was also paid to the aspect of increasing motivation to learn a foreign language in the works of such authors as O.G. Alulina (2005), I.L. Belykh (2004), E.A. Stepanova (2003).

\subsection{Hypothesis}

Based on the problems of this study, the hypothesis can be considered the assumption that teaching a foreign language in higher education will be more effective if:

- Students are aware of the conceptual principles of the organization of a foreign language system;

- There is the development of a conscious orientation of students to improve the quality of foreign language activities;

- At the stage of presenting new lexical units and speech patterns, attention is paid to the conceptualization of vocabulary with the aim of its awareness and understanding, taking into account professional orientation;

- A complex of exercises is created and introduced into the educational process in order to increase the level of students' communicative competence based on a conceptual approach to the formation of foreign language activities.

\section{Research Methodology}

\subsection{The Tasks of the Research}

In this study, the following tasks were set: 1) To explore the main aspects of the conceptualization of teaching a foreign language; 2) To identify the possibilities of information and communication support of teaching a foreign language in a university; 3) To consider the potential of a conceptual approach to teaching foreign language speech; 4) To consider opportunities to improve the development of skills to use vocabulary in foreign language communication; 5) To analyze the features and benefits of taking into account the conceptual approach to the formation of foreign language activities.

\subsection{Theoretical and Empirical Methods}

To test the hypothesis, various methods were used to complement each other: A theoretical analysis of psychological, pedagogical and methodological literature; Summarizing the experience of teaching English; Analysis of programs and textbooks on lexicology and speech practice; Questioning and interviewing; Students' selfassessment of the level of development of vocabulary skills in foreign language communication; Written and oral survey, testing of students; Pedagogical experiment; Analysis of research results.

\subsection{The trial Infrastructure and Stages of the Research}

The basis of the study was The Institute of International Relations и The Institute of Psychology and Education of Kazan (Volga region) Federal University. The study was conducted in three stages:

At the first stage (2014-2015) - The state of the problem in the scientific literature and teaching practice was investigated; The initial research positions have been developed; Empirical material was collected; The nature of students' attitudes to problems associated with the study of a foreign language was analyzed; The opportunities for productive learning of a foreign language in terms of the conceptual nature of this process were identified; The conceptual possibilities of teaching foreign language speech in the process of students' learning a foreign language are considered.

XLinguae, Volume 13 Issue 4, October 2020, ISSN 1337-8384, ISSN 2453-711X 
At the second stage (2016-2017) - A study was conducted on best practices in teaching foreign languages and methods of teaching them; A working hypothesis of the study was formulated; A technique for developing skills in the use of vocabulary in foreign language communication in the process of learning a foreign language was developed; The survey was conducted by testing students and teachers according to the method of expert assessments, managing the analysis and verification of student work, quantitative and qualitative analysis of pedagogical phenomena using the methods of mathematical statistics.

At the third stage (2018-2019) - An experimental verification was carried out of the possibilities of taking into account the main aspects of conceptuality when teaching a foreign language; The effectiveness of the implementation of the proposed conceptual approaches in teaching a foreign language was studied; The results of this research were recorded; Final wording of the provisions on formation of the foreign language training system in the context of its conceptuality has been implemented.

\subsection{Possibilities of Information and Communication Support of Teaching a Foreign Language in a University}

We believe that formation of the foreign language training system in the context of its conceptuality necessarily implies the creation of an information and communication environment conducive to solving a number of foreign language teaching tasks: firstly, to construct a language that is close to reality and exerts an intellectual and emotional impact on students necessary information of a linguistic nature; secondly, to provide students with wide access to reference, educational, methodological, and culture-intensive foreign language information (reference books, dictionaries, interactive excursions, etc.); thirdly, to form the ability to find and use the most relevant information related to the language; fourthly, to effectively organize the independent work of students in the self-improvement of a foreign language outside the audience. Hence, it is possible to structure a conceptual model of an adaptive information and communication system for teaching a foreign language at a higher educational institution, taking into account all its possibilities. The main thing is that this system should be organically linked with the system of access to learning content (for example, in the conditions of an audience or when students work independently). For example, the information exchange of a student with the system in the case of work in the classroom is also carried out using individual tablet computers with a wireless connection (they are issued in class). As for the information exchange of students with the system in the case of distance learning, it is carried out using university information networks and the Internet, which presupposes the availability of a digitized educational-methodical database on specific language topics (meaning relevant video and audio materials). The same applies to the learning management system, which provides for the registration, identification and authorization of students, as well as tests students according to specified criteria and analyzes their results. This system uses a data model in which all the initial data of the student with his grades, points scored, degree of mastering of the material, etc. are recorded. It is also important to note that the system provides for the support of teachers in the event of emergency situations when working with the learning environment, as well as providing them with substantive training for working with information and communication technologies.

Information and communication support of the process of teaching a foreign language involves the formation of intercultural competence in students, in addition to cognitive competencies, and the development of their communicative abilities, which would contribute to an adequate behavior in a cultural environment where they speak another language. In this regard, on the basis of electronic content (e-books, interactive games, various external electronic resources, etc.), an educational model is implemented in a virtual environment related to the development of skills for 
independent learning of a foreign language, taking into account self-regulation of education. For example, students through self-assessment tests have constant feedback regarding their own results, the ability to accelerate and improve the quality of the learning process according to their learning goals. Moreover, web-based methods simplify the development of various tools to support formative assessment, including horizontal (with students) and vertical (with the teacher) dialogue, debate, and teamwork. All this contributes to the development of students' susceptibility to the language; mastering language skills (reading, speaking, listening, writing); activation of oral interaction in the target language; enhancing cognitive potential in studying the difficulties of a foreign language, etc.

Of particular note in the methodological plan is the use in teaching a foreign language, for example, Internet technologies that create an active language environment, where text messages are exchanged in the target language, which is very useful in teaching writing skills. So, Wiki features allow you to edit someone else's information directly from your browser. In this case, the point is that the Wiki replaces textbooks by using available content, which could facilitate communication among teachers and students. The possibilities of using Internet technologies in the study of a foreign language today allow the following to be done: to create and place websites and personal presentations online; participate in international Internet conferences, seminars and other network projects; exchange presentations between students from different countries; communicate with residents of English-speaking countries via e-mail, etc.

As for the possibilities of information and communication support of the process of teaching a foreign language in the conditions of a higher education institution, their effectiveness can be seen in organizing students' independent work, for example, in linguistics based on an electronic workshop, which is a comprehensive system that allows them to quickly address various tasks when performing tasks information sources (linguistic terms dictionary, interactive table, textbook article, etc.). The choice of help here depends on the student, on his ability to assess the language problem in front of him and to choose the supporting resource necessary for its solution, which, in turn, develops his regulatory and information competence. The main thing is that the mechanisms for managing the student from task to task, as well as support and control mechanisms are involved in the mode of independent work with a computer.

\subsection{Conceptual Possibilities of Training Foreign Language Speech}

The purpose of teaching a foreign language is to master students' forms of oral and written communication, as well as expanding foreign language vocabulary in terms of semantics, synonyms, adequacy and relevance of its use (this includes active work on vocabulary, constant expansion of lexical material, definition of its semantics; further - primary consolidation of lexical units in speech patterns and the development of skills to use vocabulary in various forms of foreign language communication). Considering the conceptual approach to teaching foreign language speech, we note that today there is a widespread transition from the educational paradigm of knowledge and skills to the competence paradigm, which implies competenceoriented training, in particular, of a foreign language, which is reflected in the modernization of Russian education. On this basis, language education implies that a university graduate should have the following achievements: to know the basic phonetic, lexical, grammatical, word-formation phenomena; patterns of functioning of the foreign language under study and its functional varieties. A university graduate must also possess the ethical and moral standards of behavior adopted in a foreign culture society; be ready to use speech patterns in social situations; be able to translate in compliance with the rules of lexical equivalence with the observance of grammatical, syntactic and stylistic norms. In this regard, the result of learning a

XLinguae, Volume 13 Issue 4, October 2020, ISSN 1337-8384, ISSN 2453-711X 
foreign language should be the mastery of the student's foreign language communicative competence. This is an important cognitive component, which is based on the individual's need to learn the language as a means of forming and expressing thoughts, and hence his understanding of the conceptual skills of using a foreign language. And here the central role both in the process of cognition and in speech activity in mastering the linguistic features of the language belongs to the student himself. And since the key concept in speech is the concept of the meaning of words, then at the stage of presenting new lexical units to students, it is important to pay attention to the conceptualization of the vocabulary with a view to its deep awareness and understanding by them in the organization of foreign language communication.

In this regard, we have developed a block of exercises with a conceptual approach to training a foreign language in order to expand students' knowledge about the use of speech samples of English in the framework of the topics studied. To do this, when working with speech samples, we included them in the second and subsequent sessions on a similar topic in order to update the previously studied vocabulary, to expand and consolidate the material. The system of exercises offered by us consists of the following stages. At the first stage, mental workout is carried out, involving students in the subject of the lesson, for example, by using the brainstorming technique, when students by leading questions and answers to them based on speech patterns try to formulate a conceptual idea of the topic given. At the second stage, students are to distinguish relevant speech patterns related to topics that would conceptually combine the input vocabulary, its semantics and polysemy in the proposed language situation. At the third stage, students are invited to fill in the gaps with speech patterns in sentences that represent complete thematic phrases. At the fourth stage, students answer questions using new lexical expressions, compose their own texts on the situation with the studied speech patterns, or prepare a short monologue.

Thus, within the framework of the conceptual approach to teaching foreign language speech, the priority is to form a student as a linguistic person who has the ability to create and perceive texts that differ in their structural and linguistic complexity, depth and accuracy of reflection of reality, as well as a specific target orientation. And to enrich the methodology as a basis, one should refer to the following positions:

- High-quality speech is a phenomenon that permeates the daily lives of people, their language, thinking and activity;

- Training foreign language speech is the development of students' understanding of complex and often unstructured phrases (for example, idioms, parallelism, inversion, paraphrase, etc.);

- Speech as such carries certain values which are reflected in the culture, consistent with this language system (this includes a dictionary as an inventory of ready-made units and grammar as a mechanism for combining them).

Thus, the understanding of the conceptualization of foreign language speech pushes the standard framework for understanding linguistic reality, allows for cognitive level to penetrate into another culture and language. Hence, the mastery of competent foreign language speech will always be relevant to the professional of any level.

\section{Results}

\subsection{Development of Skills to Use Vocabulary in Foreign Language Communication}

In the process of developing the skills of using vocabulary in foreign language communication, special attention is paid to semantics (the science of the meaning of words), where each element carries a certain functional load: the word contains a sound and graphic form; the concept reflects certain characteristics of a class of words; the idea carries in itself the personal views of communicators of 
communication on the topic under discussion. Thus, pronouncing the phrase, we transmit a message consisting of a certain lexical material, which is determined by our own world outlook. For example, the phrase "A sprawling linden grows in our yard" at the same time carries the message that the item is in the named place; it is understood that this tree belongs to a particular type of plant; one can see the association of its size. And here the teacher's task is to clearly define the concept, so that it sets the situational framework for the application of each element (we imagine a certain yard in which a large tree called a linden tree is located); i.e. this definition of the concept is outlined in detail by certain characteristics in the form of specific words. And here, when developing skills to use vocabulary, it becomes important for students to learn various ways of expressing communication in a communicative direction, such as: A method of subject-predicative relations (the subject and his active action: "I am writing you a letter"; The subject and his state: "I miss our home"; The subject and his qualitative characteristic: "You think of me, but ignore me"); The method of expressing speech by a grammatical construction (combination of a cardinal number with a noun; use of a personal pronoun in the genitive case with a preposition; use of indefinite pronouns in interrogative and narrative sentences); The way of expressing a logical construct (for example, the noun in the instrumental case in the passive structure); The way of expressing a predicate (for example, an adjective in the form of a comparative or superlative degree; The way of expressing motion verbs in idiomatic constructions (for example, come to an agreement, go bankrupt); The method of expressing logical-semantic relations in a sentence (object constructions: Complex Object, The Objective Participial Construction, the Subjective Participial Construction; consistent and inconsistent definitions on the extended lexical and grammatical material: transmitted by adjective, gerund, infinitive, participle, participle, pronoun, noun, noun with a preposition and a definitive subordinate clause).

Hence, the most important task of a teacher is to form a clear understanding of each foreign language concept on the basis of clarification and explanation. In this regard, different methods are used to develop the skills of using vocabulary in foreign language communication, among which the most common is the description and explanation of vocabulary when introducing it into a speech construction in accordance with a given communicative task. However, just a descriptive method can cause a student boredom, so it is advisable to supplement it with a method such as exemplification (giving examples), i.e. selection of a specific lexical unit to a specific communicative situation. The next common method is contrasting when a general concept (for example, the verb "to make") requires an exact lexical unit for communication (for example, variants of the verbs "to create", "to produce", "to manufacture"). At the same time, in order to achieve the best results in the development of vocabulary skills, it is advisable to combine several methods in the work, taking into account the efficiency and strength of learning skills.

\subsection{The Procedure and Results of the Experiment}

In organizing the experiment on the stated hypothesis of this study, we proceeded from the fact that formation of the foreign language training system in the context of its conceptuality should take into account the development of the following skills in university students: Mastering knowledge of a foreign language and the organization of its system; Mastering the skills of understanding vocabulary with regard to its professional orientation; The formation of the student's goal-setting to improve the quality of his foreign language activities; The ability to structure lexical and grammatical material in foreign language communication; The ability to correctly use speech patterns in foreign language speech; The formation of self-organization competency with the intensification of speech and mental activity; The development

XLinguae, Volume 13 Issue 4, October 2020, ISSN 1337-8384, ISSN 2453-711X 
of intercultural competencies that promote adequate behavior in the foreign cultural environment. In this regard, we focused on the use of various tests that process such basic groups of exercises as: overview test; grammar test; a test on the stock of words, on the contextual application of relevant vocabulary; test for the ability to work with texts; audio testing, etc. Work on the criteria for the effectiveness of learning a foreign language in the context of its conceptuality was carried out in the 2018-2019 academic year: initially - in September 2018, secondly - in May 2019 in one experimental and one control group. The control group consisted of 18 students of The Institute of Psychology and Education of Kazan (Volga region) Federal University, who study a foreign language without taking into account the conceptual approach to this process; The experimental group included 15 students of The Institute of International Relations of this university, studying a foreign language taking into account the conceptual approach to this process. Diagnostic results are presented in Table 1.

Table 1: The development of students' skills in learning a foreign language in the context of its conceptuality

("Plus" means an increase in indicators in\% for the period September 2018 - May 2019)

\begin{tabular}{|c|c|c|}
\hline $\begin{array}{l}\text { Criteria for the } \\
\text { effectiveness of learning a } \\
\text { foreign language in the } \\
\text { context of its } \\
\text { conceptuality }\end{array}$ & $\begin{array}{l}\text { Control group (learning } \\
\text { a foreign language } \\
\text { without taking into } \\
\text { account the conceptual } \\
\text { approach to this process) }\end{array}$ & $\begin{array}{l}\text { Experimental group } \\
\text { (learning a foreign } \\
\text { language, taking into } \\
\text { account the conceptual } \\
\text { approach to this process) }\end{array}$ \\
\hline $\begin{array}{l}\text { Mastering knowledge of a } \\
\text { foreign language and the } \\
\text { organization of its system }\end{array}$ & $+9 \%$ & $+52 \%$ \\
\hline $\begin{array}{l}\text { Mastering the skills of } \\
\text { understanding vocabulary } \\
\text { with regard to its } \\
\text { professional orientation }\end{array}$ & $+6 \%$ & $+65 \%$ \\
\hline $\begin{array}{l}\text { The formation of the } \\
\text { student's goal-setting to } \\
\text { improve the quality of his } \\
\text { foreign language activities }\end{array}$ & $+8 \%$ & $+56 \%$ \\
\hline $\begin{array}{l}\text { The ability to structure } \\
\text { lexical and grammatical } \\
\text { material in foreign } \\
\text { language communication }\end{array}$ & $+5 \%$ & $+44 \%$ \\
\hline $\begin{array}{l}\text { The ability to correctly } \\
\text { use speech patterns in } \\
\text { foreign language speech }\end{array}$ & $+2 \%$ & $+48 \%$ \\
\hline $\begin{array}{l}\text { The formation of self- } \\
\text { organization competency } \\
\text { with the intensification of } \\
\text { speech and mental } \\
\text { activity }\end{array}$ & $+1 \%$ & $+46 \%$ \\
\hline $\begin{array}{l}\text { The development of } \\
\text { intercultural competencies } \\
\text { that promote adequate } \\
\text { behavior in the foreign } \\
\text { cultural environment }\end{array}$ & $+4 \%$ & $+47 \%$ \\
\hline
\end{tabular}


Compared with the results of the control group, a steady growth in all factors can be observed in the experimental group. Thus, according to the results of diagnostics of the totality of questions and tasks presented to students with the aim of a comprehensive quantitative assessment of the quality of readiness for learning a foreign language, we observe that the dynamics of increasing the language level of students who participated in the experiment exceed the similar dynamics of the control group. This may indicate the effectiveness of the work we did in the course of experimental work to increase students' ability to master a foreign language, taking into account the conceptual approach to this process. The dynamics of indicators of students mastering knowledge of a foreign language and the organization of its system also testifies to the formation of their self-organization competence in enhancing speech and mental activity on the basis of their mastery of understanding vocabulary, taking into account its professional orientation. At the same time, the number of students with a narrow range of correct use of speech samples in foreign language speech has decreased.

Thus, the conceptual approach to teaching a foreign language showed that the development of students' ability to structure vocabulary and grammar material in foreign language communication based on self-organization skills in expanding a vocabulary in a foreign language helps them develop the ability to correctly use speech patterns in a foreign language, taking into account conceptual understanding of vocabulary in the context of its professional orientation, which allows them to further develop an understanding of the organization of a foreign language system, and hence - to enhance the student's conscious focus on improving the quality of their activities through the development of foreign language communicative competences. All of the above suggests that the study confirmed basic hypothesis and allowed to increase the level of motivation for further study of a foreign language. However, this does not settle all the questions related to the development of students' skills in using a foreign language in the context of its conceptuality in order to ensure high-quality foreign language communication. Further research is required by the implementation of the following aspects of this process in various forms: Activation of the possibilities of self-education in the framework of virtual learning of a foreign language; Expanding the range of extracurricular work of students in order to form their readiness to put their knowledge into practice, etc.

\section{Discussions}

So, our analysis of the features of teaching a foreign language showed that the construction of the system of this process in the context of its conceptuality acquires the status of the most important educational aspect in the university, which involves solving problems such as:

- Initial monitoring of students' language training in order to increase independent work on the language;

- Analysis of the content of electronic educational resources (textbooks, study guides, teaching aids, etc.) in order to correct and clarify the lexical base for organizing the practice of foreign language speech;

- The introduction of new means of teaching a foreign language, determining their methodological effectiveness in accordance with the task of developing a linguistic personality, taking into account the formation of communicative competencies;

- Expansion of the complex of didactic forms of conducting classes to ensure a rich classroom work of students in the language;

- Development of a virtual environment of foreign language communication in order to solve the problem of developing intercultural competence among students; 
- Development of tools for current and final control of foreign language acquisition by students at each stage of their education at the university.

And here, in connection with the solution of these problems, it is very important (due to the frequent absence of an active language environment) direct interaction during the educational process. In this case we are talking about the process of linguistic activity carried out as part of the constant speaking in a foreign language. This conceptual approach to teaching a foreign language directly or indirectly involves the development of the functions of the language, which captures such areas as linguistics, semiotics, sociology, cultural studies, ethics, etc. This teaching model is conceptually based on a direct information-rich dialogue between the teacher and the student (or students), which provides a clear prerequisite for an active stimulating learning process, leading to improved results in mastering a foreign language.

The productive dialogue itself (conversation in a foreign language) is formed in the lesson with the help of open and correct questions and answers, so when creating a dialog space, students actively acquire knowledge, especially when learning languages. And in this context, structural elements such as the syntactic element, the stylistic element, the communicative element and the cultural element are conceptually used. In the course of the study, it was found that all these elements, mutually concise, are reflected in the common pragmatic element, which provides motivation for foreign language communication, thus moving students to a deeper study of a foreign language. This gives reason to believe that the construction of a foreign language learning system in the context of its conceptuality can be considered as the result of a quality education in the field of language teaching.

\section{Conclusion}

So, the considered aspects of teaching a foreign language in the context of its conceptuality relied primarily on the assertion that at present the foreign language is becoming the most important means of communication and cooperation in the process of a real communicative situation. And one of the conditions for successful foreign language communication is the formation of a high level of language skills. However, despite the many theoretical and practical studies being carried out, there remains the problem of the need for the widespread use of the virtual environment and digital content to improve the teaching of a foreign language, which implies, ultimately, the creation of favorable conditions for organizing productive social communication in any area of an individual's life. At the same time, there is a need for cultural awareness of the modern young man, which creates an urgent need to contribute to him in his intercultural and linguistic development. This also lies in the conceptual context of teaching a foreign language, when university teachers must create conditions for the development of intercultural communication competencies among students in order to form their willingness to interact in a multicultural environment. Hence, language teaching and approaches to the study of a different language and culture should move from a descriptive nature to multilateral direct actions, which mean interaction and communication in a foreign language, which should lead, in our opinion, to the transformation of students' self-awareness and their openness to the world. And for this, educational content in the context of its conceptualism involves the creation of prerequisites for the empathic relations of all subjects of the educational process; for students to understand their own culture and language in conjunction with the values of another cultural environment, thereby increasing the degree of integration into the overall international educational infrastructure. Hence, the relevance of updating the methodology and content of teaching foreign languages is obvious with a focus on the real interests and needs of the modern student. 


\section{Acknowledgments}

The work is performed according to the Russian Government Program of Competitive Growth of Kazan Federal University

\section{Bibliographic references}

ALULINA, O.G. 2005. Personality-oriented learning a foreign language for students of non-linguistic specialties. PhD thesis. Moscow, $190 \mathrm{p}$.

BABAYANTS, A.V. 2005. Technology for stimulating real communication in a foreign language. In: Foreign languages in school, vol. 3, pp. 60-66. ISSN 0130-6073. BELYKH, I.L. 2004. Formation of motivation of students' learning in the process of professionally-oriented additional study of a foreign language: $\mathrm{PhD}$ thesis. Krasnoyarsk.

BOLDYREVA, L.B. 1987. Training of monologic speech of students of the first year of a language university with reliance on educational texts (on the material of the English language): $\mathrm{PhD}$ thesis. Leningrad.

BONDAREVSKAYA, E.V. 2000. Theory and practice of personality-oriented education. Rostov-on-Don: Publishing House of the Rostov Pedagogical University. ISBN: 978-5-7507-0131-5.

BYRAM, M. - FENG, A. 2004. Culture and language learning: teaching, research and scholarship. Cambridge: Cambridge University.

DEVITSKAYA, Z.B. 2008. Psycholinguistic study of the assimilation of vocabulary in educational multilingualism: $\mathrm{PhD}$ thesis. Kursk.

ELUKHINA, N.V. 2002. The role of discourse in intercultural communication and the method of forming discursive competence. In: Foreign languages in school, vol. 3, pp. 9-13. ISSN 0130-6073.

GAPONTSEV, V.L. - FEDOROV, V.A. - GAPONTSEVA, M.G. KHUZIAKHMETOV, A.N. 2019. Description Language of Educational Content Structure: Possibilities of Modern Mathematics. In: Eurasia Journal of Mathematics, Science and Technology Education, vol. 15, n. 3, https://doi.org/10.29333/ejmste/103031. ISSN 1305-8215.

GARDNER, R.C. 1983. Learning another language: A true social psychological experiment. In: Journal of Language and Social Psychology, vol. 2, pp. 219-239. ISSN: 0261927X.

GOLIKOVA, L.V. 2005. Formation of the professional communicative competence of non-linguistic high school students on the basis of the project technology of teaching: PhD thesis. St. Petersburg.

GRACHEV, V.V. 2007. Theoretical bases of personalization of educational process in the higher school: $\mathrm{PhD}$ thesis. Moscow.

ISHKOV, A.D. 2004. Communication of components of self-organization and personal qualities of students with the success of educational activity: $\mathrm{PhD}$ thesis. Moscow.

ISKANDAROVA, O.Yu. 2000. Theory and practice of forming a professional communicative competence of a specialist in another language: $\mathrm{PhD}$ thesis. Orenburg. ISKHAKOV, R.H. - STURIKOVA, M.V. - DERCACH, I.O. - SMIRNOVA, S.V. MIROSHNICHENKO, V.I. - RIBAKOVA, L.A. 2019. Applied Bachelor Degree Programme as the Direction of Mobile Social Teachers Training in the Conditions of Professional and Mobile Practice. In: Eurasia Journal of Mathematics, Science and Technology Education, vol. 15, n. 3, https://doi.org/10.29333/ejmste/103030. ISSN 1305-8215.

ISKRIN, S.A. 2004. Modeling of situations of communication in the process of teaching a foreign language, vol. 9, pp. 40 - 44. ISSN 0130-6073.

XLinguae, Volume 13 Issue 4, October 2020, ISSN 1337-8384, ISSN 2453-711X 
IVANOVA, V.P. 2013. Development of intelligence as the basis of personal and professional development of students: PhD thesis. Moscow.

KALOSHINA, I.N. 2000. Personalized learning as a factor in the development of skills of students' self-educational activities: $\mathrm{PhD}$ thesis. Orenburg.

KERN, R. - SCHULTZ, J.M. 2005. Beyond orality: Investigating literacy and the literary in second and foreign language instruction. In: Modern Language Journal, vol. 89, no. 3, pp. 381-392. ISSN 1540-4781.

KHUSAINOVA, R.R. - VALEEV, A.A. 2018. Technological Aspect of the Development of University Students' Foreign Language Actvites. In: Astra Salvensis, Supplement 2/2018: Proceedings of the IV Internatonal Forum on Teacher Educatonn, pp.746-765. ISSN 2457-9807.

KHUZIAKHMETOV, A.N. - VALEEV, A.A. 2017. The development of university students' cognitive capacities. In: Modern Journal of Language Teaching Methods (MJLTM), vol. 7, no 2, pp. 149-158. ISSN: 2251-6204(E)

KONDRATEVA, I.G. - VALEEV, A.A. 2015. Technology of Students Professional Competences Formation While Teaching a Foreign Language. Procedia - Social and Behavioral Sciences. Vol. 191 - selected. pp. 1-2882. The Proceedings of 6th World Conference on educational Sciences. pp. 2250-2253. Available online: http://www.sciencedirect.com/science/article/pii/S1877042815025732

KUZMINA, S.V. - VLASIHINA, N.B. 2013. The development of student personal potential on the basis of competencies. Innovations in Education. In: Bulletin of the Nizhny Novgorod N.I. Lobachevsky University, vol. 3, no.1, pp. 26-32.

KVON, G.M. - VAKS, V.B. - KALIMULLIN, A.M. - BAYANOVA, A.R. SHAIDULLINA, A.R. - DOLZHIKOVA, A.V. - LAPIDUS, N.I. 2019. Developing the Informational and Digital Environment of a University: Problem Analysis and Assessment. In: Eurasia Journal of Mathematics, Science and Technology Education, vol. 15, n. 10, https://doi.org/10.29333/ejmste/109503. ISSN 1305-8215.

LIVER, B.L. 2000. The method of individualized teaching of a foreign language, taking into account the influence of cognitive styles on the process of its assimilation: $\mathrm{PhD}$ thesis. Moscow.

MASALIMOVA, A.R. - MIKHAYLOVSKY, M.N. - GRINENKO, A.V. SMIRNOVA, M.E. - ANDRYUSHCHENKO, L.B. - KOCHKINA, M.A. KOCHETKOV, I.G. 2019. The Interrelation between Cognitive Styles and Copying Strategies among Student Youth. In: Eurasia Journal of Mathematics, Science and Technology Education, vol. 15, n. 4, https://doi.org/10.29333/ejmste/103565. ISSN 1305-8215.

MOSKALENKO, M.R. - TOLSTYKH, O.A. - DOROZHKIN, E.M. SHCHERBIN, M.D. - VLASOVA, V.K. 2019. Distant Technologies in Teaching Legal Disciplines to Students of Pedagogical Training Programs. In: Eurasia Journal of Mathematics, Science and Technology Education, vol. 15, n. 3, https://doi.org/10.29333/ejmste/103033. ISSN 1305-8215.

NAZAROVA, M.V. - VALEEV, A.A. 2017. Didactic possibilities of interactive technologies in teaching a foreign language at the university. In: Modern Journal of Language Teaching Methods (MJLTM), vol. 7, no. 4, pp. 21-33. ISSN: 2251-6204.

REID, E. 2015. Techniques Developing Intercultural Communicative Competences in English Language Lessons. In: Procedia-Social and Behavioral Sciences, vol. 186, pp. 939-943. ISSN 1877-0428.

SABIROVA, E.G. - LATYPOV, N.R. - VALEEV, A.A. - VALEEVA, R.A. 2018. Features of Personalized Teaching a Foreign Language at Non-linguistic Faculties of the University. Innovative Technologies and Learning. ICITL. Lecture Notes in Computer Science, vol. 11, pp. 317-328.

STEPANOVA, E.A. 2003. The game as a means of developing interest in learning the language. In: Foreign languages in school, vol. 3, pp. 12-19. ISSN 0130-6073. 
SYSOEV, P.V. 2006. Integrative teaching of grammar: research on the material of the English language. In: Foreign languages at school, vol. 6, pp. 25-31. ISSN 0130-6073. TSETLIN, V.S. 2000. The Real Situations of Communication in the Lesson. In: Foreign Languages in School, vol. 3, pp. 71-75. ISSN 0130-6073.

VINNIKOVA, O.M. 2017. Methods of conceptual linguistics as a means of teaching a foreign language, In: Philology and linguistics, vol. 2, pp. 44-46. ISSN 2412-4028 ZHANG, Y. 2017. Supporting English Language Learners in Social Studies: Language-focused Strategies. In: The Social Studies, vol. 108, n. 5, pp. 1-6. ISSN 0037-7996.

Words: 8203

Characters: 54766 (30,43 standard pages)

Prof. Agzam A. Valeev, Doctor of Education

Department of Foreign Languages,

Institute of International Relations

Kazan (Volga region) Federal University,

18 Kremlyovskaya Street,

420008 Kazan

Russia

agzam.valeev1952@yandex.ru

Assoc. Prof. Larisa I. Tararina, $\mathrm{PhD}$

Department of Linguistics and Translation

Russian State Social University

4 Wilhelm Pieck Str., build.5

129226, Moscow

Russia

1t31@mail.ru

Assoc. Prof. Maria A. Khvatova, PhD

Department of Jurisprudence, Intellectual Property and Forensic Expertise

Bauman Moscow State Technical University, Moscow

5 2nd Bauman Street, build. 1

105005, Moscow

Russia

Xvatovama@rambler.ru

Assoc. Prof. Olga O. Shalamova, PhD

Department of East Languages

Pacific National University

68 Karla Marksa Street

680000 Khabarovsk

Russia

pikapika@bk.ru 